\title{
Fronteiras entre meios e formas em Cabra marcado para morrer
}

\author{
Esther Império Hamburger
}

"Vivi uma experiência maravilhosa, fui lá e fiz um filme" (Eduardo Coutinho sobre Cabra, em Eduardo Coutinho, filme de Carlos Nader, 2015)

Resumo: O documentário Cabra marcado para morrer (1964-1984) apresenta uma combinação original de elementos oriundos da prática do Centro Popular de Cultura da União Nacional dos Estudantes (CPC da UNE) que produziu o filme, da experiência televisiva do diretor na equipe do Globo Repórter e da prática dos cinemas diretos. Identificar nos fragmentos de materiais filmados pelo CPC entre 1962 e 1964 em diversos locais do Nordeste e compilados com materiais filmados no início dos anos 1980 de maneira específica em 1984 no Rio de Janeiro revela imbricações interessantes entre agendas intermediáticas. Olhar essas relações em Cabra permite pensar o filme como expressão da autocrítica do cineasta em relação a formas pré-64 de filmar. Permite também discutir a obra documentária do cineasta como investigação sucessiva em torno do cinema como meio de expressão de relações de alteridade. Um cinema de investigação, de interação e de performance que privilegia o universo popular em busca de alternativas ao cinema de representação.

Palavras-chave: documentário; cinema; televisão; história.

Abstract: Media and aesthetic boundaries in Twenty Years After (1964-1984) - This documentary performs an original combination of elements that were present in theater and film productions by the Students Union's mobile cultural arm, the Culture Popular Center - CPC, and elements that would appear in director's Eduardo Coutinho's later work as a member of Globo Reporter (a rare in Brazil television incursion in documentary, that lasted roughly from 1973 to 1984). The film also brings elements of cinema vérité and direct cinema. To focus on the relations between these fragments shot in different moments in time, and in different places reveals potent intermedial relations, and helps to interpret the film as an expression of the director's critique of his own previous ways of filming. This paper traces connections between this reflexive work, and his later experiments - a series of films that can be considered as parts of a conceptual investigation about film as performance and interaction, and affect, in lieu of film as representation.

Keywords: documentary; movies; television; history. 


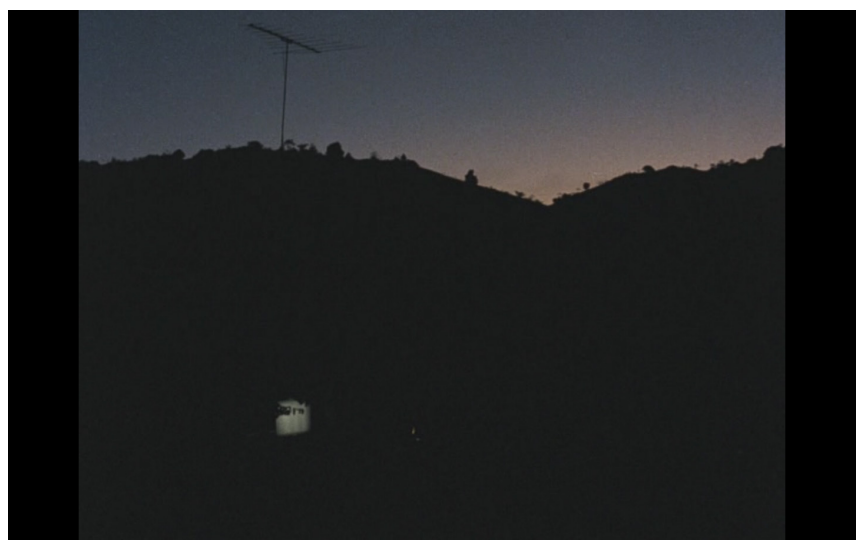

Fig.1. Primeiro quadro de Cabra Marcado para Morrer, versão restaurada distribuída em 2014.

A silhueta da colina contra um céu azul ao entardecer revela, no alto, espetada, a forma ereta e esguia de um mastro que sustenta uma antena de televisão, destaque à esquerda no quadro. A "espinha de peixe" a que se referia Bye, bye, Brasil (Carlos Diegues, 1979) se opõe a uma forma retangular branca que por um instante aparece iluminada no quadrante esquerdo inferior da tela, no mesmo eixo da antena. Em seguida, refletores estrategicamente posicionados iluminarão a cena escura: uma tela de cinema improvisada na frente de uma casa ao pé do morro. No centro do quadro, e na frente da tela, dois homens carregam a bobina de um projetor $16 \mathrm{~mm}$ instalado sobre uma mesa.

Os primeiros 30 segundos de Cabra marcado para morrer (1964-1984) sugerem que o filme versa sobre o cinema, meio original das imagens em movimento, impressas quadro a quadro em película. O registro da antena no alto do morro inspira o contraste entre o filme que será exibido e filmado a seguir e a programação do meio eletrônico que se expandia naquele início dos anos 1980. A TV alcançava regiões até então não integradas à rede nacional que difundia a partir dos grandes centros urbanos onde os conteúdos eletrônicos eram - e conteúdos digitais ainda são - majoritariamente fabricados. O cinema, meio em extinção e anacrônico, velado pela TV, que o substituiu como diversão de massa. Mas esse cinema trará imagens de personagens locais que, com poucas exceções, estão e estavam ausentes das imagens de televisão.

Cabra pode ser visto como filme-arquivo (FRANÇA, 2010) de imagens das classes populares (RAMOS, 2008) ou de estilos cinematográficos. Cabra combina de maneira original convenções do cinema direto, e do cinema verdade, mas não abre mão da voz over. O filme recupera registros do que teria sido um filme que se aproximaria do formato clássico e engajado, e acrescenta a voz do diretor em primeira pessoa, para abordar a um só tempo a história de luta, de luto, e de relação com a obra de participação coletiva que teria sido o primeiro longa-metragem produzido pelo CPC - Centro Popular de Cultura da UNE (União Nacional dos Estudantes) em 1964. 
A experiência cinematográfica se redefine quando se pode manipular o ritmo, pausar, recuar e/ou avançar (MULVEY, 2006). A cópia do filme recentemente restaurado em 2K, como adverte a cartela no início do DVD distribuído em 2014, permite revisitar a obra e especular sobre as relações intermediáticas que caracterizam suas texturas variadas. A versão final de Cabra deixa entrever, ainda que fragmentariamente, convenções estilísticas adotadas no filme de 1964 que incluíam a encenação possivelmente relacionada a outros cinemas latino-americanos e ao Terceiro Cinema, ou seja, a um cinema moderno, mas específico ao terceiro mundo e a regiões como o Nordeste.

A versão finalizada deixa entrever esses fragmentos para em contraste propor formas não encenadas, que dispensam o roteiro e valorizam a interação entre o diretor presente de corpo inteiro em quadro e os personagens com quem compartilha a memória do primeiro set de filmagem. Identifico, nos fragmentos de materiais fílmicos do CPC captados entre 1962 e 1964 em diversos locais do Nordeste e compilados de maneira específica em 1984 no Rio de Janeiro, imbricações entre agendas diferentes presentes ao mesmo tempo no cinema continental e brasileiro, em contraste com a agenda transnacional. Elementos do cinema reflexivo de Coutinho em Cabra podem ser identificados em trabalhos anteriores e posteriores do diretor, em vídeo, película e digital. A reflexão sobre a criação da imagem popular, como sugere o nome da instituição que o diretor fundou com o cartunista Claudius Seccon e onde manteve um escritório até o fim da vida, marca uma filmografia que de maneira fragmentada transcendeu a indagação original.

\section{O primeiro Cabra}

A rápida, porém sugestiva, primeira sequência colorida é interrompida por um corte brusco para imagens de arquivo em preto e branco. Os sete minutos e meio subsequentes apresentam montagem complexa, repleta de multicamadas sonoras e visuais, um início que antecipa a relevância da montagem insinuante e complexa de Eduardo Escorel como elemento chave da sintaxe do filme. ${ }^{1}$ A montagem articula o assassinato do líder camponês João Pedro Teixeira, em 1962; a história do primeiro Cabra sobre a morte de João Pedro, cuja filmagem acabou transferida de Sapé, na Paraíba, para Vitória de Santo Antão, em Pernambuco, e que nesse trânsito perdeu o elenco de participantes reais e as locações em que viveu o líder para, em compensação, ganhar participantes e locações no primeiro engenho desapropriado; a história do golpe militar em 1964, que além de interromper as filmagens, marcou o início da ditadura que governou o Brasil nos 20 anos seguintes; as mudanças que aconteceram no país ao longo dessas duas décadas de regime militar; a história de vida das pessoas que fizeram parte da equipe de atores do filme interrompido entre os anos de 1964 e 1981; a história de João Virgílio, líder da Liga Camponesa de Vitória de Santo Antão e da comunidade do Engenho da Galileia. O filme

1 O reconhecimento do valor da montagem levou Jean-Claude Bernardet a considerar Escorel coautor do filme. (BERNARDET, 2003 [1984]). 
conta também a história da viúva de João Pedro, Elizabeth Teixeira, a solidariedade com a luta do marido, o envolvimento com o filme, esconderijo, prisão, fuga para o exílio no sertão, a relação complicada com os filhos abandonados no percurso, o resgate durante a segunda etapa de filmagem, como sugestão do efeito imediato de libertação que o cinema pode produzir, redimindo-se da exposição que ele possa ter estimulado. O filme conta também algo da história do diretor, parte do CPC da UNE e que, vinte anos depois, repensa seu modo de filmar.

Planos sucessivos descrevem a vida cotidiana de pessoas pobres residentes em habitações precárias sobre palafitas à beira da água. Uma canoa surge por detrás de um barraco. Uma mulher de costas alimenta um porco na porta de casa. Meninos carregam caranguejos para vender, o porto ao fundo. Os planos imagéticos captados sem som ilustram a Canção do subdesenvolvido de Carlos Lyra e Chico de Assis, apresentada como "um clássico do CPC". Ouvimos o refrão: "É um país subdesenvolvido". A palavra "subdesenvolvido" repetida obsessivamente nomeia a condição dos lugares e das pessoas que vemos e que os movimentos articulados no CPC lutavam para superar. No plano sonoro, esse pequeno trecho cantado por coro feminino é seguido por outro, dessa vez, um fado lusitano em voz masculina de tom grave. O sotaque português pontua "...e passado o período colonial...", situando ironicamente o país que mantém a condição estrutural de dependência no período pós-colonial.

Um minuto se passou. Uma voz masculina grave entra em over: Abril de 1962. A voz over com seu sotaque nortista não se apresenta. Ela permanece a voz sem corpo, externa à filmagem, a chamada voz do dono - alternativa local à expressão voz de Deus - inserida a posteriori para explicar. Os créditos informam que a narração é de Ferreira Gullar, poeta e presidente do CPC da UNE, autor de um cordel Cabra marcado para morrer. Gullar deu voz a inúmeros filmes daquele período. A narração profere explicações históricas que favorecem o entendimento do público dos anos 1980 sobre as origens do projeto sob a égide de instituições extintas pelo golpe militar como a UNE Volante, a caravana da União Nacional dos Estudantes que percorreu o país para promover a discussão da reforma universitária e o CPC - Centro Popular de Cultura da UNE - cujos membros viajam junto com os estudantes, pois pretendiam estimular a formação de outros centros de cultura nos estados.

Uma nova voz masculina, em off, em primeira pessoa, a voz do diretor, com seu sotaque paulistano carregado, apresenta a si mesmo, na imagem fotográfica à direita do quadro, 20 anos mais novo. A autoapresentação indica uma ruptura com os padrões estéticos dos materiais mostrados até aqui. Sua narrativa intercalada com a voz de Gullar é ilustrada por recortes de jornais regionais da época, material que sugere que os fatos narrados foram notícia. O contraste entre a voz "objetiva" e desprovida de corpo de Gullar, e a voz subjetiva do diretor a rememorar as origens de sua experiência com os personagens da história relativiza ambas as vozes. A presença de Coutinho, restrita a uma foto e de 
arquivo, nas imagens da primeira fase, contrasta com a presença abundante do diretor, em quadro junto aos personagens, nas cenas da segunda fase de filmagem.

Em 1962, a UNE Volante movimentava a cena política dos lugares que passou. O assassinato de João Pedro Teixeira, a incorporação do evento dramático ao roteiro da caravana estudantil, a decisão de filmar a história do líder assassinado, a volta em 1963 para preparar a filmagem, já com o roteiro pronto, a repressão em Sapé no início de 1964, que terminou com ocupação do Exército em uma Paraíba mais hostil aos movimentos sociais que o Pernambuco de Miguel Arraes, são eventos que situam o desenvolvimento do projeto original do filme.

A imagem da primeira página do roteiro aprovado pelo CPC mostra o título "Prólogo Documentário", seguido da descrição das imagens que realmente vieram a compor a introdução da versão final do filme. O frescor dessas imagens provavelmente filmadas durante a UNE Volante contrasta com o tom mais empostado do drama.

O primeiro Cabra era encenado. O projeto original envolvia pessoas que conviveram com o morto, muitas delas encenando seus próprios papéis. Havia um só contratado, para fazer o papel do herói. A narração seria amarrada pela voz de cantador extra-diegético que articularia e comentaria o drama da vida de João Pedro e sua família. A opção pela narração musicada ecoa a tradição repentista de contar histórias, forte no Nordeste. Porém o recurso repete o dispositivo clássico de sobreposição do plano sonoro ao plano imagético.

Embora na França, nos Estados Unidos, no Canadá, versões diferentes de cinema direto presentes na gestação dos cinemas novos questionassem a encenação e a voz over, e embora o Cinema Novo brasileiro estivesse em sintonia com esses movimentos, essa adesão, como se vê, não era total. Compartilhava-se um anseio de mudança que se traduzia em formas, pautas e temporalidades diversas, que denotam também a diversidade do movimento local.

O caráter encenado do primeiro Cabra transborda nos momentos em que a montagem deixa respirar um intervalo antes de um movimento dos personagens em cena, como que a acentuar que havia um pacto entre a equipe que filmava e as pessoas que se deixavam filmar. É o caso da sequência em que Coutinho anuncia que teve seu primeiro contato com Elizabeth na sede da Liga, antes da manifestação. É como se a multidão aguardasse o final da frase para se mover ao som de uma claquete imaginária. Em outros momentos, a exposição em sequência de diversas tomadas da mesma cena tem efeito parecido. São recursos que reforçam o tom geral de rascunho do filme incompleto; o tom de avaliação do fazer cinematográfico que o filme assume, uma espécie de comentário da obra original inacabada na textura complexa, repleta de fragmentos anotados, de indícios não verbalizados, de conversas francas, mas truncadas, que compõem a obra final.

Em 1964, o recurso à encenação, ao roteiro e à narração cantada destoavam da busca de espontaneidade que as diversas versões do cinema direto propunham. Inicialmente realizados para a televisão com câmeras 16 mm e gravadores concebidos para captar 
imagem e som com a agilidade que o meio prometia, os filmes desse movimento se distanciaram do meio televisivo, mas mantiveram o uso de equipamento leve e portátil que ajudaram a formatar. $\mathrm{O}$ filme encenado destoava também dos experimentos franceses que buscavam interações entre a equipe e personagens seja na banda sonora pós-gravada como em Eu, um negro (1958) ou na filmagem da própria preparação da equipe do filme como em Crônica de um verão (1960). Interessante notar que no segundo semestre de 1963 Coutinho participou, embora não esteja creditado, da equipe de produção de um dos primeiros documentários brasileiros com som direto, também no Nordeste, Maioria absoluta, de Leon Hirszman. ${ }^{2}$

A opção do roteiro original por um cantador mantém a convenção arraigada ao sul do Equador, pela voz extra-diegética, adicionada a posteriori com intuito de guiar o visionamento das imagens. Instrumento da pós-produção, ele se impõe ao frescor que porventura algum material imprevisto pudesse expressar. Esse cantador deveria traduzir em versos as indicações estipuladas no roteiro. Possivelmente a intenção era a de fazer um filme didático e acessível. O recurso ao canto combina com a Canção do subdesenvolvido mencionada. O coro que o Teatro de Arena de São Paulo usava como recurso narrativo clássico, da herança grega, pode ser associado ao recurso do cancioneiro, conhecidas que são aproximações entre o grupo paulistano e o CPC no Rio de Janeiro.

O primeiro Cabra estava alinhado com os filmes engajados que abundavam no Brasil e em outros países latino-americanos. As diferentes correntes que compunham o CPC e os conflitos que se manifestaram por ocasião do lançamento de Cinco vezes favela, o primeiro longa da entidade, opunham os que se interessavam por questões estéticas aos que privilegiavam conteúdos programáticos (CARDENUTO, R. , 2014). No Rio de Janeiro o CPC desenvolvia intensa atividade de teatro de rua. ${ }^{3}$ A participação de artistas oriundos do Teatro de Arena como Vianinha, Nelson Xavier e outros, na redação de esquetes e encenação improvisada nas ruas e praças públicas consumia boa parte da energia dos cepecistas nos anos imediatamente anteriores a 1964. No cinema, Marimbas, filme de 1963 de Vladimir Herzog, também bastante encenado, era associado a propostas de Fernando Birri na Escola de Santa Fé na Argentina, recebidas com desconfiança no Brasil. ${ }^{4}$

Apesar da narração em over, Jean-Claude Bernardet saúda a possibilidade de que à diferença dos filmes por ele analisados em Cineastas e imagens do povo na chave do que denominou modelo sociológico, o primeiro Cabra teria realizado algo inédito ao propor que os próprios camponeses encenassem sua luta (ao invés de falar sobre sua miséria) (BERNARDET, 2003 [1984]).

2 O projeto originalmente do CPC sobre o método Paulo Freire se transformou em documentário sobre o analfabetismo concluído pelo próprio diretor que aparece como produtor nos créditos do filme lançado já depois do regime militar instalado (CARDENUTO, R., 2008). A equipe de Maioria absoluta incluía Arnaldo Jabor (som) e Luís Carlos Saldanha (imagem), ambos ex-alunos do curso de Arne Sucksdorff onde se usou a combinação da câmera de $35 \mathrm{~mm}$ com o Nagra, equipamento de gravação de som direto. Coutinho aparece em fotos da produção (HIRSZMAN, s.d.). (www.leonhirszman.com.br em 05/02/2016).

3 Depoimento de Joel Barcelos e Nelson Xavier ao Projeto Fapesp sobre o filme Fábula, de Arne Sucksdorff. Rio de Janeiro: 2014.

4 Anotações de Lucila Bernardet. ARLB-ESC. Acervo Cinemateca Brasileira. 
Por fim, a figura de Elizabeth Teixeira, viúva de João Pedro, se sobressai como elemento de continuidade entre o primeiro Cabra e a versão final. O que vemos no trecho encenado é emblemático: Elizabeth Teixeira domina a cena, contracenando com os filhos do camponês contratado para representar o papel protagonista. Ela acompanha a família na mudança para a casa de pau-a-pique na beira da estrada. Ela canta com as crianças à mesa. Ela adverte sobre a chegada de "gente lá fora". Ela vê o marido ser preso. Ela aparece linda em primeiro plano na janela.

Nos extras do DVD Coutinho revela que era ele que filmava naquele dia em que a equipe chegou a Sapé na Paraíba, onde os camponeses preparavam uma manifestação de protesto. A revelação torna mais pessoal o olhar para a câmera da viúva e dos seis filhos de luto na imagem tableau que sinalizará o início do capítulo de cada um desses filhos do casal. A imagem revela a força e a beleza da jovem mulher; o cenho franzido sustenta o olhar de Coutinho através da câmera, uma brisa ligeira a Ihe esvoaçar os cabelos. No filme a voz do diretor conta que ali teve seu primeiro contato com Elizabeth, que concordou em participar com os filhos da filmagem da história do marido.

O peso que essa imagem adquire na versão final do filme sugere a força do encontro original que inspirou o projeto e talvez uma insuspeita paixão que justifica a persistência que resultou na finalização do filme. A menção à mediação ao legendário Francisco Julião, advogado comprometido com o movimento camponês dos anos 1950 e 1960 e que viabilizou a transferência da equipe sitiada em Sapé para Galileia, enriquece o filme com imagens de mais um líder popular. O destaque à luta camponesa ganha densidade também com a presença de João Virgílio, não no papel que lhe fora reservado no roteiro de 1964, mas como personagem a compartilhar sua própria história na liderança da primeira liga camponesa vitoriosa, em um engenho desapropriado pelo governo de Pernambuco no final dos anos 1950.

\section{Cabra sobre cabra}

Coutinho dizia que a experiência na televisão, no Globo Repórter da fase inicial em que o programa era dirigido por Paulo Gil Soares (1973 a 1982), influenciou sua maneira de filmar. Percebeu que podia chegar perto das pessoas (BRAGANÇA, 2008). Os filmes que dirigiu no programa se distinguem na forma. Sabemos de sua insistência em manter um plano de três minutos de duração em Seis dias em Ouricuri (1976). Conhecemos o uso engenhoso da vocação de narrador de Teodorico, protagonista do documentário de mesmo nome (1978) para justamente eliminar o narrador da voz over, em estúdio. Nesse filme, ouvimos a voz do diretor a perguntar de fora do quadro e vislumbramos sua silhueta sentado em uma poltrona em frente ao coronel (HAMBURGER, 2013; SACRAMENTO, 2011; SOBRINHO, 2010).

Os filmes do Globo Repórter eram feitos com câmera $16 \mathrm{~mm}$ e captação de som direto, permitindo a agilidade de movimento a uma equipe reduzida. A experiência de 
imersão no programa para o qual foi contratado em 1975 como roteirista fixo, mas onde dirigiu seis documentários, mudou a maneira de Coutinho filmar. Podemos vislumbrar essas mudanças em seus filmes para o Globo Repórter, mas é no cinema, em Cabra, que o aprendizado de Coutinho na televisão vem à tona com maior contundência.

No início dos anos 1980, em intervalos do trabalho na TV, quando Coutinho reencontra os participantes do filme original, com equipamento semelhante ao que aprendeu a usar no Globo Repórter, chegou perto e fez um filme que usa as imagens originais para elaborar as memórias do primeiro set de filmagem. A dublagem de certas falas em sincronia com as imagens tantos anos depois; a boa acolhida à equipe - apesar da repressão dos longos anos de regime militar, da falta de contato, da dispersão dos antigos companheiros, da mudança de profissão e da migração de muitos, elementos que tornavam a possibilidade de conclusão do filme remota - são indícios que sugerem a força do pacto inicial. A inabilidade em lidar com vozes dissonantes também se revelou, especialmente em relação a João Mariano (ESCOREL, 2013; MENEZES, 1994 ).

O plano que se tornaria célebre nos filmes do diretor e nos documentários inspirados em sua obra, aquele que mostra a equipe, no caso reduzida ao cinegrafista e ao técnico de som, cada um empunhando o seu equipamento portátil, além do próprio diretor, de costas, andando em direção ao local de encontro com a pessoa a ser entrevistada, aparece pela primeira vez em Cabra, quando a equipe, filmada por uma segunda câmera, de quem se afasta, segue a pé rumo à residência de Elizabeth Teixeira no exílio, pronta a libertá-la do isolamento. O plano das costas do cineasta lembra imagens semelhantes em Primary (1960), filme emblemático da emergência do cinema direto.

Porém, à diferença do filme sobre as eleições primárias no estado de Wisconsin, que consagraram John Kennedy como candidato do Partido Democrata à eleição presidencial norte-americana, Coutinho não estava a cobrir acontecimentos que até certo ponto independiam do aparato de filmagem. O cineasta provocou as situações que filmaria. A chegada em São Rafael, na Paraíba, obrigou Elizabeth Teixeira a revelar a identidade que escondera dos vizinhos, alunos e amigos. Instigada pelo diretor, a protagonista grava uma mensagem para seus filhos. O diretor os procura munido daquela mensagem em áudio e registra sua reação emocionada. Coutinho testou os limites do aparato fílmico, ainda não digital, mas já eletrônico (no som). No entanto, ao contrário do que o filme sugere, como vemos nos extras do DVD, a família nunca se reconciliou plenamente.

O projeto original de produção de um material que poderia ser utilizado nas campanhas de esclarecimento do CPC foi interrompido e abortado pela chegada repentina do Exército. A maior parte da equipe fugiu e voltou ao Rio de Janeiro. Mas a liderança camponesa foi presa e torturada. João Virgílio ficou com a visão prejudicada. Elizabeth Teixeira viveu exilada, com falsa identidade e afastada dos filhos. O filme lançado em 1984 expõe a desigualdade com que a repressão tratou os membros da equipe do filme original. Em seus retornos sucessivos, registra a cada visita os deslocamentos e conflitos que talvez em alguma medida se relacionassem a suas visitas anteriores. 
A chegada de Coutinho com certeza liberou Elizabeth. Em 1984 ela veio ao Sudeste para participar de festivais e do lançamento do filme. O cineasta buscou também retribuir financeiramente a protagonista por sua participação ajudando por exemplo na compra de uma casa. No entanto, nas conversas nos extras do DVD há indícios das relações de alteridade que se repõem, dos desdobramentos inadvertidos dos acontecimentos fílmicos que insistem em reverberar. Os extras informam que o filho de Elizabeth que era operário em uma obra no Rio de Janeiro voltou a Sapé e terminou morto depois de entrar em conflito com um irmão e o avô. Apesar da mediação insistente do cineasta, Elizabeth nunca recuperou a intimidade com a maioria de seus filhos. Uma das filhas no Rio de Janeiro afirma finalmente que a família inteira sempre soube onde vivia a sua mãe durante os anos de exílio.

A retomada das filmagens de Cabra se beneficia das formas de filmar desenvolvidas no trabalho no Globo Repórter, mas dispensa as limitações do programa, que exigia cortes rápidos e abusava da então mais que anacrônica narração em off de um apresentador que fala a partir do estúdio sem nunca ter ido a campo. A oposição às convenções do programa se baseava no projeto tardio de documentário que poderia ser denominado "moderno" em oposição ao já mencionado "clássico" (XAVIER, 2003); (RAMOS, 2008). $\mathrm{Ou}$ "antropológico" em oposição ao "sociológico", se quisermos ser fiéis a uma nomenclatura que surgiu em função da filmografia nacional (TEIXEIRA, 2004).

Claudia Mesquita (MESQUITA, 2016) situa Cabra e Peões como filmes que se diferenciam na obra do diretor porque lidam com material de arquivo e com a memória. Acrescento que entre os dois filmes é possível diferenciar um do outro porque, no primeiro, o diretor compartilha com os personagens de seu filme a experiência da filmagem em 1964, elemento central na rememoração. Coutinho não repetiria esse dispositivo em nenhum de seus filmes posteriores, onde em geral optou por situações em que suas relações com personagens se iniciaram no momento da filmagem.

O trabalho concluído resulta de material filmado em diversas ocasiões sem roteiro prévio, com a presença de Coutinho em cena, aberto à memória dos participantes sobre as primeiras filmagens e ao relato de vida delas desde então. Em 1984, o uso da primeira pessoa do singular, em uma voz over subjetiva que dialoga e contrasta com a voz over clássica é um dos elementos que distingue e valoriza Cabra, abrindo uma possível associação bastante contemporânea entre o filme de Coutinho e a discussão sobre o filme ensaio. ${ }^{5}$ Consuelo Lins aponta a excepcionalidade da voz subjetiva de diretores no cinema. ${ }^{6}$ Ismail Xavier admite a forma ensaio em relação a outra obra-prima de Coutinho, essa plenamente inserida no debate contemporâneo, Jogo de cena (XAVIER, 2014).

5 Algumas referências nesse debate são Alter (2007) e Rascarolli (2008), que problematizam o uso do termo a partir de referências clássicas como Adorno (1962).

6 Consuelo Lins em "O ensaio fílmico e a narração" lembra a voz subjetiva de Glauber Rocha em Câncer (19681972) (LINS, 2007). Vale lembrar que Eduardo Coutinho atua no filme de Glauber, que apresentará anos depois, também de corpo inteiro, o programa Abertura na TV Tupi. 
Ao expor sua maneira antiga de filmar Coutinho talvez tenha flertado com o ensaio em Cabra, porém há certamente no filme elementos do que Bill Nicholls denominaria documentário de intervenção. Antes que essa discussão se transforme em um exercício taxonômico, o que por si só esvaziaria a potência do possível esforço ensaístico, se reservarmos ao termo um teor de liberdade e irreverência formal que resistiria a classificações simples, penso que pode ser produtivo pensar uma possível inquietação ensaística que perpassa a preocupação de Coutinho com as implicações éticas e políticas envolvidas no fazer documentário.

Difíceis de classificar, os documentários de Coutinho a cada novo trabalho recolocam as relações entre cinema e política a partir da interação em cena entre diretor e sujeitos de seus filmes. O dispositivo cada vez mais apurado valoriza o acontecimento fílmico em detrimento de elementos que lhe precedem ou que lhe são externos (como materiais sonoros ou imagéticos extra-diegéticos, postos a posteriori na montagem), ou de cortes no interior de planos (que poderiam interromper raciocínios).

A partir de Cabra cada projeto pode ser pensado como uma interjeição específica, em uma obra atenta aos desafios postos pelo debate brasileiro e internacional sobre a possibilidade de um cinema que pensa, cuja potência estaria não na força de imposição de ideias definidas a priori, mas na proposição de dispositivos capazes de engendrar materiais plenos de indagações. Cada filme insinua conexões interessantes e rupturas, compreensões e mal-entendidos, continuidades e lacunas, entre discussões fílmicas locais e internacionais, entre documentário, fantasia e performance, teoria e prática.

Em certo sentido essa inquietação pode ser entendida como contrária ao projeto original de Cabra marcado para morrer, que, em seu estilo encenação roteirizada de história já ocorrida, se aproxima do docudrama. Não interessam as histórias em si, mas as formas de encená-las. (Aqui outra diferença com diversas vertentes do cinema direto que em geral submetem o aparato cinematográfico a eventos e/ou pessoas que lhe antecedem.) Coutinho aprimora método de filmagem e montagem como se quisesse fazer um cinema a prova de efeitos perversos, evitar dispositivos e estilos que reverberam para além das intenções e/ou controle de diretores e equipes e que podem de uma forma ou de outra se voltar contra personagens. Seus filmes podem ser vistos como sequência de indagações inconclusivas, mas que acumulam, avançam, recuam na problematização do drama.

Paradoxalmente, a sequência de realizações levou o diretor que se notabilizou por filmar pessoas desconhecidas em locais que usualmente não aparecem na televisão ou no cinema ao que Consuelo Lins denominou "afastamento do mundo". O cineasta célebre pela pesquisa persistente em torno da oralidade popular radicaliza a reflexão sobre a encenação, ao propor a atuação de pessoas de diversas origens sociais, fora de seus lugares, em palcos fechados. O dispositivo valoriza o movimento da personagem ao se candidatar a participar de um filme. Em alguns casos a conversa deixa de ser a matéria que se torna a performance musical (como em Canções) ou a atuação mesmo (como em 
Jogo de cena ou Moscou). Ou seja, um cinema que se propõe a questionar o próprio estatuto da imagem cinematográfica, que contribui para expressar a potência do mundo animado pela fabulação de pessoas singulares para além de determinações sociológicas, caminha em direção ao privilégio da encenação sobre paisagens e eventos do mundo. Encenações bastante diferentes das encenações propostas no primeiro Cabra. Mas se o cineasta que mais se dedicou a refletir sobre os desafios postos à expressão fílmica das desigualdades brasileiras, e que mais frequentou e procurou dispositivos visuais para potencializar paisagens populares, voltasse ao morro em tempos em que a guerra deixou de ser particular, como será que filmaria?

Esther Imperio Hamburger é professora do departamento de Cinema, Rádio e TV da ECA-USP.

ehamb@usp.br

\section{Referências}

BERNARDET, J. C. Cineastas e imagens do povo. $2^{a}$ Edição. São Paulo: Cia das Letras, 2003 [1984]. BRAGANÇA, F. (Org.). Eduardo Coutinho. Coleção Encontros. Rio: Beco do Azougue Editorial, 2008. CARDENUTO, R. Discursos de intervenção: o cinema de propaganda ideológica para o CPC e o Ipês às vésperas do golpe de 1964. 2008. (Mestrado). PPGMPA, Universidade de São Paulo, São Paulo.

O cinema político de Leon Hirzsman (1976-1983): Engajamento e resistência durante o regime militar brasileiro. 2014. (Doutorado). PPGMPA, Universidade de São Paulo, São Paulo.

DE MENEZES, P. R. A. A questão do herói-sujeito em cabra marcado para morrer, filme de Eduardo Coutinho. Tempo Social; Rev. Sociol. USP, v. 6, n. 12, p. 107-126, 1994

ESCOREL, E. Vinte Perguntas para Eduardo Coutinho. Questões Cinematográficas. Rio de Janeiro: Revista Piauí. 20152013.

FRANÇA, A., HABERT, ANGELUCCIA E PEREIRA, MIGUEL O Globo Repórter sob o lema setentista: Ocupar espaço, amigo, eu digo, brechas. Rio de Janeiro: Compós 2010.

HAMBURGER, E. I. "Coutinho e a TV". In: OHATA, M. O. (Ed.). Eduardo Coutinho. São Paulo: Cosac Naify, 2013

LINS, C. "O ensaio no documentário e a questão da narração em off." In: FREIRE FILHO, João \& HERSCHMANN, Micael. Novos rumos da cultura da mídia: indústrias, produtos, audiências, p. 143-157. Rio de Janeiro: Mauad X, 2007.

MESQUITA, C. Entre agora e outrora: a escrita da história no cinema de Eduardo Coutinho, Galáxia, São Paulo: PUC, n.31, abril, 2016.

MULVEY, L. Death 24x a Second, stillness and the moving image. London: Reaktion Books, 2006.

RAMOS, F. Mas Afinal, o que é mesmo o documentário? São Paulo: SENAC, 2008. 
SACRAMENTO, I. Depois da Revolução, a Televisão: cineastas de esquerda no jornalismo televisivo dos anos 1970. Rio de Janeiro: Pedro e João Editores, 2011.

SOBRINHO, G. A. Sobre Televisão Experimental: Teodorico, Imperador do Sertão de Eduardo Coutinho, e o Globo Repórter. Revista Eco-Pós, v. 13, n. 2, p. 67-84, 2010.

TEIXEIRA, F. E., Ed. Documentário no Brasil - Tradição e Transformação. São Paulo: Summus Ed., 2004.

XAVIER, I. Indagações em torno de Eduardo Coutinho - e seu diálogo com a tradição moderna. Cinemais, v. 36, n. outubro / dezembro, p. 221-236, 2003.

A teatralidade como vetor do ensaio fílmico no documentário brasileiro contemporâneo. Aniki:

Revista Portuguesa da Imagem em Movimento 1.1, p. 33-48, 2014. 